\title{
"Detachment of the carinal hook following endobronchial intubation with a double lumen tube"
}

Ana C Rocha ${ }^{1,2^{*}}$, Mafalda G Martins ${ }^{1}$, Luísa I Silva ${ }^{1}$ and José M Nunes ${ }^{1}$

\begin{abstract}
Background: Carinal hooks increases difficulty at endotracheal intubation. Amputation of the carinal hook during passage and malpositioning of the tube to the hook are some of the potential problems related with left-sided Carlens double lumen tube (DLT). This article reports an amputation of the hook during a difficult selective intubation and aimed at calling the attention to complications associated with DLTs and the importance of fiberoptic bronchoscopy.

Case presentation: A 68 year-old woman was scheduled for right-sided thoracotomy in whom blind DLT insertion was performed. Narrowed trachea causes difficulty in rotating the DLT $90^{\circ}$ counter-clockwise. After carinal hook was noticed upon visual inspection of the DLT, fiberoptic bronchoscopy was used to remove the missing part (with the use of forceps) from the right mainstem bronchus.

Conclusion: Insertion of DLTs with carinal hook is associated with technical problems and potentially lifethreatening hazards have discouraged their use. Fiberoptic evaluation and repositioning solves most of the problems. Although amputation of the carinal hook has not been previously reported, clinicians should be alert. This case report emphasizes the utility of the fiberoptic bronchoscopy in the operating theatre for placement, positioning and inspection of the carinal hook DLT.
\end{abstract}

\section{Background}

Double-lumen tubes with fixed carinal hooks facilitated proper placement and minimized further tube advancement during positioning. However, potential problems and complications were associated with carinal hooks. These included a higher incidence of insertion difficulty, laryngeal trauma and amputation of the hook during placement $[1,2]$. Several methods for proper placement and positioning of DLTs are available in [3-6]. We describe a case of a carinal hook's amputation after blind insertion of left-sided polyvinylchloride Carlens DLT (SUMI ${ }^{\circledR}$, Portex Inc., Mexico). The foreign body was removed from the right mainstem bronchial lumen with a fiberopticguided technique and, although a successful outcome was achieved, we failed the placement of DLT with fiberoptic bronchoscopy.

\footnotetext{
* Correspondence: carolinassrocha@gmail.com

${ }^{1}$ Department of Anesthesiology, ULS de Castelo Branco, Portugal

Full list of author information is available at the end of the article
}

\section{Case Report}

A 68 year-old woman (weight $74 \mathrm{~kg}$, height $162 \mathrm{~cm}$ ) with a pathological fracture of the fourth thoracic vertebrae (T4) was scheduled to undergo total removal of the vertebrae by a right transthoracic approach. Her past medical history included hypertension controlled with $20 \mathrm{mg}$ enalapril once a day. Preoperative airway examination revealed a class II Mallampati with a normal mouth opening and normal dentition, a thyromental distance of $6.0 \mathrm{~cm}$ and limited neck extension. Paraplegia was present and no other abnormalities were detected on physical examination. All laboratory values, chest $\mathrm{x}$-ray and 12-lead electrocardiogram were normal. The patient was premedicated with $10 \mathrm{mg}$ diazepam on the night before surgery along with overnight fasting. After adequate preoxygenation, anesthesia was induced with $50 \mu \mathrm{g}$ fentanyl, TIVA of propofol and remifentanil, and muscle relaxation was achieved with $50 \mathrm{mg}$ rocuronium. Conventional direct laryngoscopy was performed and Cormack and Lehane grade was II (only the posterior extremity of the
C Biomed Central

C 2011 Rocha et al; licensee BioMed Central Ltd. This is an Open Access article distributed under the terms of the Creative Commons Attribution License (http://creativecommons.org/licenses/by/2.0), which permits unrestricted use, distribution, and reproduction in any medium, provided the original work is properly cited. 
glottis visible). A 37F left-sided polyvinylchloride Carlens DLT (SUMI ${ }^{\circledR}$, Portex Inc., Mexico) was placed using standard technique, although difficult to achieve because of a narrowed trachea. The patient's lung was ventilated through both lumens of the tube, with tracheal cuff inflated, but a resistance at manual ventilation was felt immediately after intubation. Chest auscultation revealed bilaterally equal and diminished breath sounds with pulse oximetry saturation decreasing from $99 \%$ to $96 \%$. DLT was removed and before a second left endobronchial intubation attempt, examination of the DLT showed no carinal hook (Figure 1). An $8.0 \mathrm{~mm}$ ID single-lumen endotracheal tube was placed and then fiberoptic bronchoscopy was performed. An increased in pulse oximetry saturation (from 95\% to 99\%) with normal chest auscultation was noted. The fiberoptic examination showed the carinal hook located in the right mainstem bronchus, which was removed with the use of forceps. No evidence of a traumatized airway was noted. Two further attempts were made with another 37F Carlens DLT, by a different physician and with the aid of fiberoptic bronchoscopy (external diameter: $4.5 \mathrm{~mm}$ ). However, DLT rotation failed because of a narrowed trachea. Smaller DLTs were not available. Thoracotomy was performed in left position with an $8.0 \mathrm{~mm}$ ID single-lumen endotracheal tube. The patient's hemodynamics was stable throughout this period. Her postoperative period was uneventful.

\section{Conclusions}

Potential problems with carinal hook have been observed [1,2], however this is the first case reported of amputation of the carinal hook in a 37F left-sided polyvinylchloride Carlens DLT (SUMI ${ }^{\circledR}$, Portex Inc., Mexico).

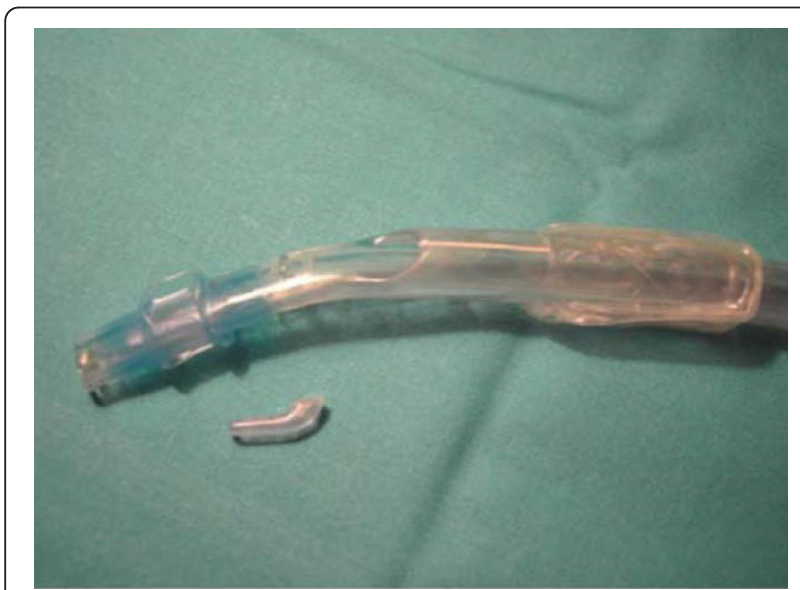

Figure 1 Amputation of the carinal hook (arrows) in a leftsided polyvinylchloride Carlens DLT (SUMI ${ }^{\circledR}$, Portex Inc., Mexico).
The exact mechanism leading to the amputate ion of the carinal hook is obscure. Rigid structures, narrow passages and manufacturing defect are possible [7].

In this case, desaturation and resistance to manual ventilation have alerted to a probably malpositioned DLT. In fact, tracheal narrowing was visualized by conventional laryngoscopy and insertion of the DLT occurred with some difficulties. The potential cause for the hook detachment was a narrowed trachea. Prompt action to remove the airway foreign body by bronchoscopy solved the patient's problem without adverse consequences. Although fiberoptic bronchoscopy is the accepted standard for appropriate positioning and confirmation of DLT [8], it was not performed in the first attempt. No double-lumen tube positioning method is fail-safe and unsuccessful replacement of another DLT with the aid of fiberoptic bronchoscopy occurred.

The present case has demonstrated that carinal hooks can be hazardous. It also highlights the importance of the availability of fiberoptic equipment in the operating theatre to promote proper DLT positioning and inspection of the carinal hook DLT, to reconfirm that no amputation had occurred.

Assuming a manufacturing defect of the 37F left-sided polyvinylchloride Carlens DLT (SUMI ${ }^{\circledR}$, Portex Inc., Mexico.), until now no answer regarding the event was given by the DLT company.

\section{Consent}

Written informed consent was obtained from the patient for publication of this case report. A copy of the written consent is available for review by the Editor-in-Chief of this journal.

\section{Acknowledgements}

Written consent for publication was obtained from the patient or their relative.

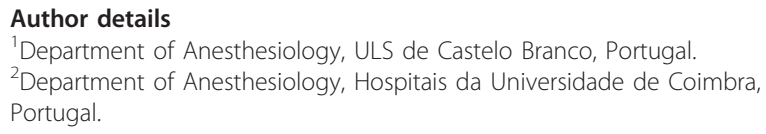

${ }^{1}$ Department of Anesthesiology, ULS de Castelo Branco, Portugal. ¿Department of Anesthesiology, Hospitais da Universidade de Coimbra, Portugal.

\section{Authors' contributions}

ACR collected data and drafted the manuscript. MGM collected the data and helped to write the manuscript. LIS and JMN reviewed the final manuscript. All authors read and approved the final manuscript.

\section{Competing interests}

The authors declare that they have no competing interests.

Received: 19 January 2010 Accepted: 28 October 2011 Published: 28 October 2011

\section{References}

1. Wilson WC, Benumof JL: From Anesthesia for thoracic surgery.Edited by: Miller RD. Miller's Anesthesia. Philadelphia: Churchill Livingstone; , 6 2005:1847-1939. 
2. Al-Metwalli RR, Mowafi HA, Ismail SA: Double-Lumen Tube Placement Using a Retractable Carinal Hook: A Preliminary Report. Anesth Analg 2009, 109(2):447-450.

3. Campos JH, Hallam EA, Van Natta T, Kernstine KH: Devices for lung isolation used by anesthesiologists with limited thoracic experience: comparison of double-lumen endotracheal tube, Univent torque control blocker, and Arndt wire-guided endobronchial blocker. Anesthesiology 2006, 104(2):261-266

4. Eagle CC: The relationship between a person's height and appropriate endotracheal tube length. Anaesth Intensive Care 1992, 20(2):156-160.

5. Chang PJ, Sung YH, Wang LK, Tsai YC: Estimation of the depth of leftsided double-lumen endobronchial tube placement using preoperative chest radiographs. Acta Anaesthesiol Sin 2002, 40(1):25-29.

6. Bahk JH, Oh YS: A new and simple maneuver to position the left-sided double-lumen tube without the aid of fiberobtic bronchoscopy. Anesth Analg 1998, 86(6):1271-1275.

7. Pollak Y, Kogan A, Grunwald Z: Double-lumen tube malfunction caused by carinal hook. Anesthesiology 1995, 83(3):639.

8. Cohen E: Double-lumen tube position should be confirmed by fiberoptic bronchoscopy. Curr Opin Anaesthesiol 2004, 17(1):1-6.

\section{Pre-publication history}

The pre-publication history for this paper can be accessed here:

http://www.biomedcentral.com/1471-2253/11/20/prepub

doi:10.1186/1471-2253-11-20

Cite this article as: Rocha et al: "Detachment of the carinal hook following endobronchial intubation with a double lumen tube". BMC Anesthesiology 2011 11:20.

\section{Submit your next manuscript to BioMed Central and take full advantage of:}

- Convenient online submission

- Thorough peer review

- No space constraints or color figure charges

- Immediate publication on acceptance

- Inclusion in PubMed, CAS, Scopus and Google Scholar

- Research which is freely available for redistribution

Submit your manuscript at www.biomedcentral.com/submit 